\title{
Constructing Evaluation Model Based on AHP
}

\author{
Zhao Dan \\ Department of Mathematics, Anshan Normal University, Anshan, 114007,, \\ People's Republic of China
}

\begin{abstract}
First we analyzed the ways of evaluating practice teaching quality and the problems existing. Second based on AHP cleared the steps of constructing evaluating model. Then we analyzed the factors of effecting and restricting the quality and efficiency of the system for practice teaching. Evaluation index were selected abiding by operability, rationality, comprehensive and quantitative. Then according to questionnaire and statistical analysis of the relevant data we obtained the weight values of every factor based on AHP and set up scientific, quantitative evaluation model. Last it passed consistency test and showed that the model was scientific and rational.
\end{abstract}

Keywords: AHP, quantitative, evaluation model, consistency test

\section{Introduction}

The evaluation of practice teaching quality is an important part of the whole practice teaching system. But it is difficult to carry on evaluating quantitative or qualitative because of the diversity of content and the flexibility of organization form. At present, the evaluation of practice teaching quality is still at exploring and the initial stage, the shortages and defects still exist. For example: evaluation way is single, focus more excessively on the result than the process. The quantitative of evaluation index are lack of scientific basis, often based on experience or simple Arithmetic mean. There may be large deviation between evaluation result and actual situation. Then directly affect the accuracy of qualitative also the accuracy of quantitative. For the above problems, we try to apply AHP to set up scientific and quantitative evaluation model and select index following operability rationality、comprehensive and quantitative. Then we used AHP to seek the weight values of every factor and the comprehensive weight vectors and test passing consistency test.

\section{The Implement of AHP on Practice Teaching Quality Evaluation}

\section{1) Brief Introduction of AHP}

The advantage of AHP proposed by American T.L. Satty is that qualitative and quantitative are combined which is highly logic 、systemic 、 simplicity and practicality. It is an effective decision-making method for every level and multi-objective planning and decision-making problem. Its basic principle is regarding the complex problems as a big system, then draw orderly hierarchy of every interrelated factor by analyzing many factors of every system. Then ask experts to analyse and judge every factor of every level objectively, giving relatively important quantitative expression. Then set up mathematic model, calculate the relatively important weight values of all factors in every level and sort, last test whether or not satisfy the consistency. 


\section{2) The Basis and Steps of Setting up the Model}

First make the problem systematic and hierarchy, set up a structure model. Decompose related factors from top to down to several levels according to the properties, every factor of the same level subordinates the factors of the above one, or affected the factors of the above one. Generally there are the highest level named target level which denotes the achieving goal of applying AHP, the middle level denotes the intermediate links concerned when applying AHP, often strategy level、 restricted level、 criteria level and so on, the bottom denotes various measures provided to the final target.

Second set up comparative judge matrix. When to compare $\mathrm{n}$ factors $x_{1}, x_{2}, \cdots, x_{n}$ of some level how to affect the above target $Z$, use comparing two factors to quantitative "the importance". Each time choose two positive numbers $x_{i}, x_{j}$, the positive number $b_{i j}=\frac{x_{i}}{x_{j}}$ denotes the rate of $x_{i}$ and $x_{j}$ related to the above target $Z$.The matrix $A=\left(b_{i j}\right)_{m \times n}$ obtained named comparative judge matrix, obviously $b_{i j}>0, b_{j i}=\frac{1}{b_{i j}}, b_{i i}=1$. The value of $b_{i j}$ referred to the way proposed by Satty, he quoted number 1 to 9 and their reciprocals as scaling, the meaning seeing Table 1 .

Table 1. Scaling Table

\begin{tabular}{llll}
\hline scaling & meaning & scalin & meaning \\
\hline 1 & $\begin{array}{l}\text { Denotes two factors compared, have the same } \\
\text { importance }\end{array}$ & 7 & $\begin{array}{l}\text { Denotes two factors compared, The } \\
\text { former is strongly important than the latter } \\
\text { Denotes two factors compared, The } \\
\text { former is extremely important than the } \\
\text { Denotes two factors compared, The former is } \\
\text { a little important than the latter }\end{array}$ \\
5 & $\begin{array}{l}\text { Denotes two factors compared, The former is } \\
\text { apparently important than the latter }\end{array}$ & $\begin{array}{l}\text { The between values of the above } \\
\text { reciprocals }\end{array}$ & $\begin{array}{l}\text { judgement } \\
\text { If the rate of factor } x_{i} \text { and } x_{j} \text { is } b_{i j} \text {,then that of } x_{j} \text { and } x_{i} \text { is } \frac{1}{b_{i j}}\end{array}$ \\
\hline
\end{tabular}

Then making single sort and consistency test.Computing the biggest eigenvalue $\lambda_{\max }$ of every comparative judge matrix and the corresponding eigenvector $w_{i}$, the eigenvector $w_{i}$ satisfied consistency will be the sort weight vector of the under level regarded as more important than the upper level. This process named level single sort.

Test every comparative judge matrix, the steps as follow:

(i) computing consistency index $C I, C I=\frac{\lambda_{\max }-n}{n-1}$;

(ii) find average random consistency index $R I$, see in Table 2;

(iii) computing random consistency rate $C R, C R=\frac{C I}{R I}$.

Table 2. Average Random Consistency Index $R I$

\begin{tabular}{ccccccccccc}
\hline Dimension of comparative matrix & 1 & 2 & 3 & 4 & 5 & 6 & 7 & 8 \\
\hline RI & 0.00 & 0.00 & 0.58 & 0.90 & 1.12 & 1.24 & 1.32 & 1.41 & 1.45 \\
\hline
\end{tabular}


When $C R<0.1$, the comparative judge matrix is regarded as consistent. Then its eigenvectors are regarded as weight vectors. Or it is need to adjust the matrix again until satisfy the consistency.

Last compute comprehensive weight vectors and make comprehensive consistency test, namely level general sort and consistency test. The above vectors are the ones that one group of factors to their upper level some vector. Finally it is need to get sort weight vectors that every plan of the lowest to the general target. Integrating the final sort weigh vectors top-down. The formula that computing every factor of the general sort weight vectors are

$$
w_{i j}{ }^{(l)}=\sum_{j=1}^{m} w_{i j}{ }^{(l-1)} p_{i j}{ }^{(l)}(i=1,2, \cdots n)
$$

The comprehensive consistent rate is

$$
C R^{(l)}=\frac{\sum_{j=1}^{n} C I_{j}{ }^{(l)} w_{i j}{ }^{(l-1)}}{\sum_{j=1}^{n} R I_{j}{ }^{(l)} w_{i j}{ }^{(l-1)}}
$$

When $C R<0.1$, the final level sort is consistent, or adjust comparative judge matrix again.

\section{Analysis of Effecting and Restricting the Factors of Practice Teaching Quality and Set up Evaluating Model}

\section{1) Analysis of Effecting and Restricting Practice Teaching Quality Factors}

Agreement: $b_{j}$ denotes final target index; $c_{j}$ denotes second evaluation index; $d_{j}$ denotes third evaluation index; $e_{j}$ denotes fourth evaluation index.

Analyzing the factors that restrict practice teaching quality and efficiency, there are three basic factors namely final target index: object factors $b_{1}$, management factors $b_{2}$ and subject factors $b_{3}$. The three are complementary and affect together the improvement of practice teaching quality. The object and the subject factors restrict the potential quality and efficiency of the practice teaching, functioning by the management. The management factors restrict the practical quality and efficiency.

The object factors are the general object conditions that the produce、research、social and practice are conducting. It is divided into condition factors $c_{1}$, environment factors $c_{2}$ and other object factors $c_{3}$ according to its role in the practice teaching activity. The condition factor is an essential object condition. Without it the potential of practice teaching cannot be explored effectively. According to its activity content it can be divided into producing practice condition $d_{1}$ 、 experiment practice teaching condition $d_{2}$ 、social practice condition $d_{3}$ 、 research practice condition $d_{4}$ and so on. According to the type of practice teaching activity, the environment factor it can divided into social practice teaching environment $d_{5}$ 、 producing practice teaching environment $d_{6}$ 、 research practice teaching environment $d_{7}$. The management factor contains: management operating mechanism $c_{4}$ 、 management conditions $c_{5}$ 、 management ideas $c_{6}$ 、 management principles $c_{7}$ 、 management system $c_{8}$ 、 management action $c_{9}$ 、 management guidelines target $c_{10}$ and so on.

The subject factors are the all subjects that accomplish practicing teaching activity. It is 
divided into practice factor $c_{11}$ and teaching factor $c_{12}$. Here practice factor contains managers、 workers $d_{8}$, researchers $d_{9}$ in the research practice. Teaching factor is the subject of teaching activity containing teachers $d_{10}$, teaching management service staff $d_{11}$ and students $d_{12}$. The teacher factor is the leading of teaching factors. From the theory, practice teaching requirements the quality of teachers are more highly than the classroom theory. Teachers play a more important role in the teaching practice than in the classroom. Teacher factors contain the scale of the teachers team $e_{1}$ 、 qualification and titles $e_{2}$ 、 the numbers and ranks of researches $e_{3}$. Teaching management services staff are the concrete bearers of practice teaching management work. Their quality determines the level of practice teaching management service. Management services staff quality contains ability and level $e_{4}$ 、 service attitude $e_{5}$, manage mind and idea $e_{6}$. The students play double roles in the teaching practice. The students are both the acceptor in the practice teaching and the subject in the practice activity, also passive factor and active factor. The students factors contain strong sense of collaboration $e_{7}$, clear studying motive and active correct attitude $e_{8}$, strong practice ability $e_{9}$, proper practice ways $e_{10}$.

\section{2) Set up Evaluation Model}

According to the above analysis of factors that restrict practice teaching quality, set up comprehensive evaluating model.

Based on AHP, using questionnaire and expert advisory to set up the judge matrix of every index level seeing the following Table 3-13. Here the weight value $w_{i}$ of every comparative matrix obtained by the formula named root law:

$$
w_{i}=\frac{\sqrt[n]{\prod_{j=1}^{n} a_{i j}}}{\sum_{k=1}^{n} \sqrt[n]{\sqrt[n]{\prod_{j=1}^{n} a_{k j}}}}\left(a_{i j} \text { is the element of every matrix }\right)
$$

Taking the final target index as an example, the related results computed in detail as follows:

$$
\begin{gathered}
C I=\frac{\lambda_{\max }-n}{n-1}=\frac{3.02-3}{3-1}=0.01, R I^{(2)}=0.58, C R^{(2)}=\frac{C I}{R I^{(2)}}=0.0172<0.1 \\
w_{1}^{(2)}=\frac{\sqrt[3]{1+1 / 5+1 / 3}}{\sqrt[3]{1+1 / 5+1 / 3}+\sqrt[3]{5+1+2}+\sqrt[3]{5+3+1}}=0.22 \\
w_{2}^{(2)}=\frac{\sqrt[3]{5+1+2}}{\sqrt[3]{1+1 / 5+1 / 3+\sqrt[3]{5+1+2}+\sqrt[3]{5+3+1}}=0.38}=0.40 \\
w_{3}^{(2)}=\frac{\sqrt[3]{5+3+1}}{\sqrt[3]{1+1 / 5+1 / 3+\sqrt[3]{5+1+2}+\sqrt[3]{5+3+1}}}=0 .(0.22,0.38,0.40)^{\prime}
\end{gathered}
$$

Therefore, the judge matrix of the final target index can be obtained, which is summarized in Table 3. 
Table 3. Judge Matrix of the Final Target Index

\begin{tabular}{cccccc}
\hline $\mathrm{A}$ & $b_{1}$ & $b_{2}$ & $b_{3}$ & $w^{(2)}$ & Consistency test \\
\hline$b_{1}$ & 1 & $1 / 5$ & $1 / 3$ & 0.22 & $\lambda_{\max }=3.02$ \\
$b_{2}$ & 5 & 1 & 2 & 0.38 & $C I^{(2)}=0.01, \quad R I^{(2)}=0.58$ \\
$b_{3}$ & 5 & 3 & 1 & 0.4 & $C R^{(2)}=0.0172<0.1$
\end{tabular}

Similarly, Table 4 to Table 13 can be obtained in the same way, and the detail computations were omitted.

Table 4. Judge Matrix of Object Factors Index

\begin{tabular}{cccccc}
\hline$b_{1}$ & $c_{1}$ & $c_{2}$ & $c_{3}$ & $p_{1 j}{ }^{(3)}$ & Consistency test \\
\hline$c_{1}$ & 1 & 2 & 5 & 0.38 & $\lambda_{\max }=3.02$ \\
$c_{2}$ & $1 / 2$ & 1 & 3 & 0.40 & $C I_{1}{ }^{(2)}=0.01, \quad R I_{1}{ }^{(2)}=0.58$ \\
$c_{3}$ & $1 / 5$ & $1 / 3$ & 1 & 0.22 & $C R_{1}^{(2)}=0.0172<0.1$ \\
\hline
\end{tabular}

Table 5. Judge Matrix of Management Factors Index

\begin{tabular}{cccccccccc}
\hline$b_{2}$ & $c_{4}$ & $c_{5}$ & $c_{6}$ & $c_{7}$ & $c_{8}$ & $c_{9}$ & $c_{10}$ & $p_{2 j}{ }^{(3)}$ & Consistency test \\
\hline$c_{4}$ & 1 & 3 & 2 & 5 & $1 / 2$ & 4 & 2 & 0.22 & $\lambda_{\max }=7.7$ \\
$c_{5}$ & $1 / 3$ & 1 & $1 / 2$ & 3 & $1 / 4$ & 2 & 1 & 0.08 & $C I_{2}{ }^{(3)}=0.1206$ \\
$c_{6}$ & $1 / 2$ & 2 & 1 & 4 & $1 / 3$ & 3 & 1 & 0.14 & $R I_{2}{ }^{(3)}=1.24$ \\
$c_{7}$ & $1 / 5$ & $1 / 3$ & $1 / 4$ & 1 & $1 / 6$ & $1 / 2$ & $1 / 4$ & 0.04 & $C R^{(3)}{ }_{2}<0.1$ \\
$c_{8}$ & 2 & 4 & 3 & 6 & 1 & 5 & 3 & 0.33 & \\
$c_{9}$ & $1 / 4$ & $1 / 2$ & $1 / 3$ & 2 & $1 / 5$ & 1 & $1 / 3$ & 0.05 & \\
$c_{10}$ & $1 / 2$ & 2 & 1 & 4 & $1 / 3$ & 3 & 1 & 0.14 & \\
\hline
\end{tabular}

Table 6. Judge Matrix of Subject Factors Index

\begin{tabular}{ccccc}
\hline$b_{3}$ & $c_{11}$ & $c_{12}$ & $p_{3 j}{ }^{(3)}$ & Consistency test \\
\hline$c_{11}$ & 1 & $1 / 2$ & 0.33 & $\lambda_{\max }=2.02$ \\
$c_{12}$ & 2 & 1 & 0.67 & $C I_{3}{ }^{(3)}=0.02, R I_{3}{ }^{(3)}=0$ \\
\hline
\end{tabular}


Table 7. Judge Matrix of Condition Factors Index

\begin{tabular}{ccccccc}
\hline$c_{1}$ & $d_{1}$ & $d_{2}$ & $d_{3}$ & $d_{4}$ & $p_{1 j}{ }^{(4)}$ & Consistency test \\
\hline$d_{1}$ & 1 & $1 / 5$ & $1 / 3$ & $1 / 2$ & 0.08 & $\lambda_{\max }=4.19$ \\
$d_{2}$ & 3 & 1 & 4 & 5 & 0.59 & $C I_{1}^{(4)}=0.063, R I_{1}^{(4)}=0.09$ \\
$d_{3}$ & 3 & $1 / 4$ & 1 & 2 & 0.21 & $C R_{1}^{(4)}=0.07<0.1$ \\
$d_{4}$ & 2 & $1 / 5$ & $1 / 2$ & 1 & 0.12 & \\
\hline
\end{tabular}

Table 8. Judge Matrix of Environment Factors Index

\begin{tabular}{cccccc}
\hline$c_{2}$ & $d_{5}$ & $d_{6}$ & $d_{7}$ & $p_{2 j}{ }^{(4)}$ & Consistency test \\
\hline$d_{5}$ & 1 & 7 & 5 & 0.73 & $\lambda_{\max }=3.07$ \\
$d_{6}$ & $1 / 7$ & 1 & $1 / 3$ & 0.08 & $C I_{2}{ }^{(4)}=0.035, R I_{2}{ }^{(4)}=0.58$ \\
$d_{7}$ & $1 / 5$ & 3 & 1 & 0.19 & $C R_{2}{ }^{(4)}=0.0603<0.1$ \\
\hline
\end{tabular}

Table 9. Judge Matrix of Practice Subject Factors Index

\begin{tabular}{ccccc}
\hline$c_{11}$ & $d_{8}$ & $d_{9}$ & $p_{3 j}{ }^{(4)}$ & Consistency test \\
\hline$d_{8}$ & 1 & 2 & 0.67 & $\lambda_{\max }=2.02$ \\
$d_{9}$ & $1 / 2$ & 1 & 0.33 & $C I_{3}{ }^{(3)}=0.02, R I_{3}^{(3)}=0$ \\
\hline
\end{tabular}

Table 10. Judge Matrix of Teaching Subject Factors Index

\begin{tabular}{cccccc}
\hline$c_{12}$ & $d_{10}$ & $d_{11}$ & $d_{12}$ & $p_{4 j}{ }^{(4)}$ & Consistency test \\
\hline$d_{10}$ & 1 & 5 & 7 & 0.73 & $\lambda_{\max }=3.07$ \\
$d_{11}$ & $1 / 5$ & 1 & 3 & 0.19 & $C I_{12}{ }^{(4)}=0.035, R I_{12}{ }^{(4)}=0.58$ \\
$d_{12}$ & $1 / 7$ & $1 / 3$ & 1 & 0.08 & $C R_{12}{ }^{(4)}=0.0603<0.1$ \\
\hline
\end{tabular}

Table 11. Judge Matrix of Teacher Factors

\begin{tabular}{cccccc}
\hline$d_{10}$ & $e_{1}$ & $e_{2}$ & $e_{3}$ & $p_{1 j}{ }^{(5)}$ & Consistency test \\
\hline$e_{1}$ & 1 & $1 / 7$ & $1 / 3$ & 0.08 & $\lambda_{\max }=3.07$ \\
$e_{2}$ & 7 & 1 & 5 & 0.73 & $C I_{10}{ }^{(5)}=0.035, \quad R I_{10}{ }^{(5)}=0.58$ \\
$e_{3}$ & 3 & $1 / 5$ & 1 & 0.19 & $C R_{10}{ }^{(5)}=0.0603<0.1$ \\
\hline
\end{tabular}


Table 12. Judge Matrix of Teaching Management Service Staff

\begin{tabular}{cccccc}
\hline$d_{11}$ & $e_{4}$ & $e_{5}$ & $e_{5}$ & $p_{2 j}{ }^{(5)}$ & Consistency test \\
\hline$e_{4}$ & 1 & 3 & $1 / 5$ & 0.19 & $\lambda_{\max }=3.075$ \\
$e_{5}$ & $1 / 3$ & 1 & $1 / 7$ & 0.08 & $C I_{11}{ }^{(5)}=0.035 R I_{11}{ }^{(5)}=0.58$ \\
$e_{5}$ & 5 & 7 & 1 & 0.73 & $C R_{11}{ }^{(5)}=0.0603<0.1$ \\
\hline
\end{tabular}

Table 13. Judge Matrix of Student Factors Index

\begin{tabular}{ccccccc}
\hline$d_{12}$ & $e_{7}$ & $e_{8}$ & $e_{9}$ & $e_{10}$ & $p_{3 j}{ }^{(5)}$ & Consistency test \\
\hline$e_{7}$ & 1 & $1 / 5$ & $1 / 3$ & $1 / 2$ & 0.08 & $\lambda_{\max }=4.19$ \\
$e_{8}$ & 5 & 1 & 4 & 5 & 0.59 & $C I_{12}{ }^{(5)}=0.065, \quad R I_{12}{ }^{(5)}=0.9$ \\
$e_{9}$ & 3 & $1 / 4$ & 1 & 2 & 0.21 & $C R_{12}{ }^{(5)}=0.07<0.1$ \\
$e_{10}$ & 2 & $1 / 5$ & $1 / 2$ & 1 & 0.12 & \\
\hline
\end{tabular}

$$
w^{3}=\left(\begin{array}{l}
0.11 \times 0.58,0.11 \times 0.31,0.11 \times 0.11,0.58 \times 0.22,0.58 \times 0.08,0.58 \times 0.14, \\
0.58 \times 0.04,0.58 \times 0.33,0.58 \times 0.05,0.58 \times 0.14,0.31 \times 0.33,0.31 \times 0.67
\end{array}\right)
$$

$=(0.0638,0.0341,0.0121,0.1276,0.0464,0.0812,0.0232,0.1914,0.0290,0.0812,0.1023,0.0277)$

$$
\begin{aligned}
& C I^{(3)}=\left(C I_{1}^{(3)}, C I_{2}^{(3)}, C I_{3}^{(3)}\right)\left(W^{(2)}\right)=(0.01,0.12,0.02)\left(\begin{array}{l}
0.11 \\
0.58 \\
0.31
\end{array}\right)=0.0769 \\
& R I^{(3)}=\left(R I_{1}^{(3)}, R I_{2}^{(3)}, R I_{3}^{(3)}\right)\left(W^{(2)}\right)=(0.58,0.12,0)\left(\begin{array}{l}
0.11 \\
0.58 \\
0.31
\end{array}\right)=0.783 \\
& C R^{(3)}=\frac{C I^{(3)}}{R I^{(3)}}=\frac{0.0769}{0.789}=0.09821<0.1 .
\end{aligned}
$$

Similarly, we can get the following quantum:

$$
\begin{aligned}
w^{(4)} & =\left(\begin{array}{l}
0.0638 \times 0.08,0.0638 \times 0.59,0.0638 \times 0.21,0.0638 \times 0.12,0.0341 \times 0.73,0.0341 \times 0.08, \\
0.0341 \times 0.19,0.0121 \times 0.67,0.0121 \times 0.33,0.2077 \times 0.73,0.2077 \times 0.19,0.2077 \times 0.08
\end{array}\right) \\
& =\left(\begin{array}{l}
0.005104,0.037642,0.013398,0.007656,0.024893,0.02728,0.006479, \\
0.0081070 .003993,0.151621,0.039463,0.016616
\end{array}\right)
\end{aligned}
$$

And $C I^{(4)}=0.0145284, R I^{(4)}=0.197664$, obviously $C R^{(4)}<0.1$.

$$
\begin{aligned}
w^{(5)} & =\left(\begin{array}{l}
0.1516 \times 0.08,0.1516 \times 0.73,0.1516 \times 0.19,0.1516 \times 0.19,0.039463 \times 0.08 \\
0.039463 \times 0.73,0.016616 \times 0.08,0.016616 \times 0.59,0.016616 \times 0.21,0.016616 \times 0.12
\end{array}\right) \\
& =\left(\begin{array}{l}
0.0121297,0.110683,0.028808,0.0074977,0.00315704,0.028808, \\
0.00132928,0.00980344,0.00348936,0.00199392
\end{array}\right)
\end{aligned}
$$


And $C I^{(5)}=0.00773476, R I^{(5)}=0.1257831, C R^{(5)}<0.1$.

\section{Conclusion}

In this paper, we first analyzed the existing problems in practice teaching quality system and the researching direction and target. Second based on AHP, we set up hierarchy model: constructing comparative judge matrix, single sort and consistency test, computing comprehensive weight vectors and making comprehensive consistency test, namely total sort and consistency test. Last we analyzed the factors that constraint practice teaching quality and effect. The final target factors contained object factor subject factor and management factor, here they containing many second level、 third level and fourth level index. Then set up comprehensive evaluation index system of practice teaching quality, here the weight vectors of every matrix given by the above formula, and passed the consistent test showing that the matrix constructed are rational and feasible.

\section{References}

[1] Wang Lianfang, Xu Shubai. Analytic Hierarchy Process Introduction. Beijing: Chinese People's University Press 1996, 32

[2] Yuan Zhendong. Concise mathematical modeling tutorial.Shang hai: East China Normal University Press, 2002

[3] Chen Tao, Du Shiping. Preliminary exploration on practice teaching of information and computing science in Agricultural Colleges. Journal of Sichuan Agricultural University, 2007, 25(2):235-238

[4] Satty T. L. Marketing Application of the Analysis Hierarchy Process. Management Science, 1980, 26, (7):641-656

[5] Wu Xu, Wang Xuben, et al., Watershed ecological assessment system of decision-making based on AHP method, Journal of Chengdu University: Science and Technology Edition, 2011, 38(2), 126-131

[6] Xuan Yongbo, Huang Changqiang, et al., Effectiveness evaluation of space weapon system based on gray hierarchy method, Journal of Air Force engineering University, 2011, 12(2), 32-37

[7] Wang Weigang, Chen Renliang, Multi-objective optimum design of planetary gear transmission based on AHP, Machine Design and Manufacture, 2011, 4, 39-41

[8] Wang Lili, The assessment study on potential of cleaner production using fuzzy maths and AHP, Chengdu university of Technology, 2015,12, 121-129

[9] He Qingfei, Chen Guiming, et al., Life prediction of hydraulic pump based on an improved grey neural network, China Mechanical Engineering, 2013, 24(4), 500-506

[10] Wang YD, Ding HY, Luo HB, Parameter estimation base on fuzzy membership function, Geospatial information, 2013, 11(1): 55-57

[11] Liang L, Su L T, Feng Y X, et al. Grey theory based vibration prediction for steam turbines, Thermal Power Generation, 2012, 41(10): 21-24

[12] He X, Liu W F, An intuitionistic fuzzy multi-attribute decision-making method with preference on alternatives, Operations Research and Management Science, 2013, 22(1), 36-40

[13] Sun CZ, Lin XY. Fuzzy consistent matrix based on AHP and its application. Fuzzy Systems and Mathematics, 2002, 16(3), 59-63

[14] Gu XB, Zhu Q X, Xuan D J. Complete information generated algorithm based on AHP and its application, Computer Engineering, 2006, 32(5), 32-35

[15] Wendan Zhang, Jian Lu, Yi Zhang.Comprehensive Evaluation Index System of Low Carbon Road Transport Based on Fuzzy Evaluation Method. Procedia Engineering, 2016, 137: 660-668.

[16] Arora Ela, P.Detroja Ketan. Online Monitoring for Uneven Length Batch Processes using unction Space Principal Component Analysis. IFAC Proceedings Volumes, 2013, 46 (31): 66-71.

[17] E. Stavrovsky, M .Krasilnikova, S. Pryadko. AHP and ANP as Particular Cases of Markov Chains. IFAC Proceedings Volumes, 2013, 46(9): 531-536.

[18] Davida. Nadler, Edwarde. Lawler. Quality of work life: perspectives and directions. Organizational Dynamics. 1983 winter, 11(3): 19.

[19] ILO. Decent work, report of the director general.Geneva, 1999(6):5-7.

[20] Richard Anker, Lgorcher nyshev, Philippe Eggee, Farhad Mehran, Josepha Ritter. Measuring decent work with statistical indicators. International labour review. Geneva, 2003.142(2):147.

[21] Schroeder, Fredric K. Workplace issues and placement: What is high quality employment? Work, 2007, Vol. 29, (4): 357- 358.

[22] European Commission. Taking stock of five years of the European employment strategy. Communication, 2002(7).

[23] Rafael Munnoz de Bustillo Llorente, Enrique Fernandez Mac as. Job satisfaction as an indicator of the 
quality of work. The Journal of Socio-Economics. Spain, 2005, Vol.34, 656-673.

[24] National Center for Education, Statistics. Digest of Education Statistics. NCES, 2001: 455.

[25] Hillage Pol lard. Employ ability: Developing a Frame work for Palfrey Analysis, DFEE Research Report, 1998: 85.

[26] Watts, A. G. SvanEsbroek, R. Newski Izs. For New Futures: Higher Education Guidance and Counseling Services in the European Union. Brussels VUB Press, 1998: 122.

[27] ILO. Decent work, report of the director general. Geneva, 1999, (6):5-7.

[28] Richard Anker, Lgor Chernyshev, Philippeeggee, Farhad Mehran, Joseph A Ritter. Measuring decent work with statistical in dictators international lab our review, Geneva, 2003, (142): 147.

[29] European Commission. Taking stock of five years of the European employment strategy. Communication, 2002, (7).

[30] Schroeder, Fredric k. Workplace issues and placement: What is high quality employment. Work. 2007, 29(4): 357-358.

\section{Author}

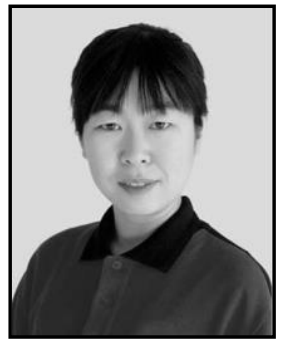

Dan Zhao, She comes from Department of Mathematics, Anshan Normal University, Anshan, China. Her

research interests include mathematical statistics and statistical analysis. 
International Journal of Grid and Distributed Computing

Vol. 9, No. 8 (2016) 